\title{
Em busca de um fórum para bioética na política pública do Brasil
}

\author{
In search of a national forum for bioethics in \\ Brazilian public policy
}

Marília Bernardes Marques

\begin{abstract}
This article focus on bi oethics as a public policy issue. It analyzes the main existing international codes on biomedical ethics and presents a bri ef review of the work of some national bioethics committees in developing countries. The author concludes by commenting on the most relevant and controversial aspects to be consi dered in the Brazilian experience. Key words Bioethics; Medical Ethics; Public Policy; Brazil

Resumo O artigo focaliza a bioética enquanto tema da política pública. Analisa os principais códi gos internacionais referentes à ética biomédica e apresenta uma sucinta revisão do trabal ho de algumas comissões naci onais de bi oéti ca de países desenvolvidos. Concluindo, a autora assinala os aspectos mais rel evantes e controverti dos a serem consi derados na experiência brasileira. Palavras-chave Bioética; Ética Médica; Política Pública; Brasil
\end{abstract}




\section{Introdução}

A missão de formular e implementar normas bioéticas tem constituído, na atualidade, não apenas no Brasil, mas em diversas outras nações, um verdadeiro desafio para uma ação multidisciplinar organizada. Simultaneamente filosófica, técnica, cultural e política, esta tarefa deve incluir, além dos julgamentos éticos dos profissionais da saúde, os enfoques da teologia e do direito e não pode prescindir da opinião da sociedade (Pessini, 1995; Garrafa, 1995; Segre \& Cohen, 1995).

Entre 1992 e 1995, a Comissão Intersetorial de Ciência e Tecnologia (CICT) do Consel ho Nacional de Saúde (CNS) analisou processos procedentes de todo o país e de todas as especialidades da medicina, contemplando relevantes aspectos éticos da experimentação em humanos. Os processos foram enviados no período 1989-1995, com o objetivo de obter credenciamento no CNS, tendo em conta a Resolução Número 1, de 1988 (CNS, 1995a), referente às normas éticas da pesquisa em saúde.

No exame dos processos, a $\mathrm{CICT}$ constatou a desatualização de alguns dos conteúdos específicos distribuídos pelos 15 capítulos da resolução, decorrente, em parte, das transformações da ciência e da tecnologia observadas no período. Por sua vez, lacunas e ambigüidades do texto criavam verdadeiros gargal os operacionais e favoreciam a interpretação dúbia da norma ao não explicitar atribuições para as comissões institucionais de bioética, para as diversas instâncias do Ministério da Saúde e, até mesmo, para o próprio CNS.

Oportunamente, o CNS (1995b) optou por deflagrar um processo de revisão das suas normas éticas. O plano para a revisão (CNS, 1995c) partia de uma ampla consulta à sociedade brasileira e constituía um grupo executivo, de composição multidisciplinar, com 15 participantes: médicos, pesquisadores, teólogos, juristas e outros membros, todos ligados a campos atinentes às questões éticas (CNS, 1995d).

Tal missão constituiu um desafio gigantesco, pois, no Brasil, a participação ampla da sociedade em um processo de tal envergadura encontra barreiras na exclusão social e cultural de grandes parcelas da população e no freqüente descrédito nas instituições públicas, infelizmente, tão disseminado entre os brasileiros nos últimos anos.

Serve de consolo saber que as dificuldades que o Brasil vem encontrando nesse campo são compartilhadas por outros países. Sem dúvida, a missão de identificar o melhor fórum e os procedimentos e orientações normativas mais adequados para lidar com as questões da bioética está presente na agenda pública de diversos países na última década deste século.

Neste texto, elaborado na expectativa de contribuir para que a sociedade brasileira seja bem sucedida na imensa tarefa que Ihe foi proposta pelo CNS, são apresentadas, inicialmente, as linhas gerais evolutivas dos códigos internacionais referentes à ética biomédica e, em seguida, algumas experiências de países desenvolvidos com comissões nacionais e comitês de ética. Finalmente, o artigo sistematiza alguns dos aspectos relevantes para a abordagem da regulação da bioética pelo Estado, no Brasil.

\section{Linhas gerais evolutivas dos códigos éticos internacionais}

Foi o horror causado pelos experimentos nazistas que estimularia a elaboração do primeiro texto de referência em bioética, de alcance internacional: o Código de Nuremberg, de 1947. Este código instituiu a obrigatoriedade do consentimento informado do indivíduo submetido às experiências biomédicas, exigência que passaria a ser a base legal de todo o sistema da bioética. Além disso, introduziu a obrigatoriedade dos pré-requisitos científicos, apoiada na soberania da responsabilidade ética do profissional.

A declaração de Helsinque, revista em Tóquio em 1975, traria três avanços significativos: na contabilização dos riscos, os interesses do indivíduo devem prevalecer sobre os interesses da ciência e, até mesmo, sobre os da sociedade; diferenciar, na obtenção do consentimento informado, aqueles indivíduos que se encontram em situações específicas de dependência e incapacidade; todo protocolo de pesquisa deve ser apreciado por uma comissão de ética independente.

A declaração de Manila, de 1981, elaborada pela Organização Mundial da Saúde e pelo Conselho das Organizações Internacionais das Ciências Médicas (CIOMS/ OMS, 1995), estabeleceu que não é possível separar apreciação científica e apreciação ética: uma experiência com seres humanos que não tenha valor científico é ipso facto contrária a ética. Quanto à composição e funcionamento das comissões de ética independentes, estabeleceu que elas deveriam acrescentar nomes de não-especialistas, suficientemente qualificados para representar os valores culturais e morais da sociedade (Edelman, 1991). 
Este último código deu um grande salto ao homogeneizar as regras éticas a serem observadas pelos pesquisadores e instituições estrangeiros nos países em desenvolvimento, sem, entretanto, adentrar na questão ética essencial do direito ao desenvolvimento. Esta questão, nos diversos foros internacionais de negociação comercial, está no cerne das atuais controvérsias sobre o patenteamento da vida, entre outros aspectos, os direitos patentários dos países em desenvolvimento e de populações nativas, advindos do aproveitamento, para usos industriais diversos, dos conhecimentos tradicionais, dos recursos originários das respectivas biodiversidades e de células humanas (Marques, 1994).

\section{Da abrangência da bioética}

A magnitude alcançada pela bioética na atualidade vai sendo revelada pela diversidade de tópicos, a qual floresce e evolui de modo acelerado e contínuo nos eventos e debates específicos acontecidos em todo o mundo, descortinando o rol das complexas preocupações de ordem moral existentes nos campos da medicina, da saúde humana e do meio ambiente (Michaelis, 1995; Macer, 1994a; Brewin, 1994; Cole, 1995; Coughilin \& Etheredge, 1995). Nos domínios da bioética, as ciências naturais, o direito, a filosofia, a sociologia e outras disciplinas valorizam um fenômeno particular desde diferentes perspectivas ou pontos de vista. O termo "bioética" expressa, portanto, em sua complexidade, muito mais a um conjunto de vozes do que a uma disciplina específica.

Internacionalmente, discute-se sobre as atribuições e a composição de comissões nacionais e de comitês institucionais de ética, novas tecnologias genéticas e patenteamento da vida, tecnologias conceptivas e de reprodução assistida, uso de tecidos fetais e de embriões humanos em pesquisas, terapêutica dos genes, transplantes de órgãos, o conceito de morte e o modo de morrer (morte cerebral e eutanásia), privatização da saúde, política e meio ambiente, experimentação em animais e em seres humanos e muitos outros temas (McShane et al., 1994).

A palavra "bioética" foi empregada inicialmente em inglês, em 1970, por Potter, incluindo temas de ética ambiental e de ética médica (Potter, 1971, apud Macer, 1994b; Pessini \& Barchifontaine, 1994; Garrafa, 1995). Nas décadas de 70 e 80, a expressão foi utilizada simultaneamente aos desenvolvimentos da biotecnologia de terceira geração e, especialmente, das suas aplicações na medicina, expressando um vasto campo de interesses, mais ou menos disfarçados, de ordem religiosa, ideológica, legal, comercial, de legisladores, de médicos, de cientistas etc. (Nature, 1995; Cole-Turner, 1995). Nos anos 90, os temas da ética ambiental ganhariam destaque, principalmente com as discussões em torno da Convenção da Biodiversidade.

Sem dúvida, a bioética ainda é dominantemente européia e americana, situando-se na fronteira da ciência e da tecnologia e repousando no respeito à autonomia do indivíduo. Ela não só é originária dos países desenvolvidos, como é neles que seus temas proliferam incessantemente.

Atualmente, diversos países europeus e a União Européia estão considerando a possibilidade de introdução de leis para regulamentar certas práticas genéticas, e alguns países, como a Noruega, já o fizeram. Até bem pouco tempo, as preocupações focalizavam os testes genéticos para doenças raras, embora importantes, e que expressam distúrbios nos padrões hereditários mendelianos. Esta ênfase mudou de direção recentemente, para doenças crônicas comuns, como o diabetes mellitus e o câncer de mama, com os testes permitindo identificar loci específicos de suscetibilidade (Annas, 1995). Antes mesmo da disseminação dos testes de suscetibilidade genética e das terapias de intervenção genética, estas novas tecnologias médicas já têm se revelado capazes de acentuar, internacionalmente, a natureza discriminatória de planos privados de seguro saúde (Harper, 1995; Whartenby et al., 1995; Hudson et al., 1995; Orkin \& Motulsky, 1995).

Consideramos que, na atualidade, o grande desafio, éinserir a bioética no processo de formulação de políticas de governo e no planejamento estratégico, visando a determinar as possíveis influências das inovações tecnológicas em medicina, sobre os serviços de saúde e sobre a sociedade (Burke, 1995; Olson, 1995).

Em trabalho anterior (Marques, 1993), desenvolvemos a hipótese de que as controvérsias que envolvem os temas da ciência e da tecnologia, combinando ética, segurança, sigilo, propriedade intelectual e temas econômicos em um emaranhado de interesses públicos e privados, foram gradual mente acompanhando, após a Segunda Guerra Mundial, a construção da liderança dos Estados Unidos em matéria de inovação tecnológica.

O status de ferramentas tecnológicas revolucionárias, sob o aspecto da economia e da medicina, alcançado pelos procedimentos mé- 
dicos baseados nos métodos e técnicas de engenharia genética tem sido, no cenário das negociações sobre comércio internacional, uma das principais razões alegadas pelos países desenvolvidos para introduzir novos procedimentos protecionistas, barrei ras regulatórias e convenções de harmonização de legislações nacionais (Marques, 1994).

Atualmente, os principais órgãos internacionais de bioética existentes são o International Bioethi cs Committe da Unesco (Paris), que vem se dedicando à tarefa de harmonizar internacionalmente os aspectos éticos suscitados pelo Projeto do Genoma Humano, e o Grupo de Assessores da Comissão Européia nas Implicações Éticas da Biotecnologia (Bruxelas). A Convenção Européia de Bioética, em elaboração, representará o primeiro texto internacional em bioética a ter efeito legal nos estados membros da Europa que a ratificarem. As Diretrizes da União Européia para Patentes em Biotecnologia também terão grande influência, nos estados membros, nas questões éticas das pesquisas em saúde, ao negarem proteção comercial às "invenções" em áreas consideradas eticamente inaceitáveis (Dodet, 1994; Butler, 1995; Koenig, 1995).

Embora a participação do poder público seja percebida como necessária, internacionalmente existem dúvidas a respeito dos limites e da eficácia da ação do Estado nas questões de natureza ética, como veremos a seguir.

\section{Descrição sucinta de algumas experiências nacionais}

O recente destaque que vem sendo dado à bioética pelos governos dos países desenvolvidos, sobretudo pelo dos Estados Unidos e pelos da Europa, é mais uma das evidências disponíveis na conjuntura internacional da imensa importância econômica, política e social alcançada pelas pesquisas científicas e tecnologias médicas e biológicas na vida daquelas nações (Keats, 1995; Macer, 1994b).

Os limites da regulação bioética variam, entretanto, de um país a outro e, em parte, as diferenças refletem o caráter recente da maioria das experiências. Por exemplo, no caso da França, com um Estado tradicionalmente centralizador e com associações profissionais relativamente débeis, legisla-se sobre a matéria bioética e mesmo o código de deontologia médica requer aprovação ministerial (Lenoir, 1991). Na Inglaterra e em outros países do norte da Europa, ao contrário, a tradição é de auto-regulação profissional.
Alguns países, como os Estados Unidos, optaram por um modelo regulamentar que, embora restrito às pesquisas financiadas pelos organismos públicos, tem, na prática, suas regras amplamente respeitadas, tanto no âmbito das pesquisas do setor público, quanto no do privado. São elas que explicam, por exemplo, por que os responsáveis pelas revistas científicas americanas somente aceitam publicar resultados de pesquisas cujos autores possam comprovar o parecer favorável, prévio, de uma comissão de ética independente (Hanna et al., 1993).

Em outros países, como Japão, Inglaterra e Alemanha, a regulamentação é parcial, sendo concernente apenas aos ensaios de medicamentos e não à pesquisa biomédica em geral. Para os experimentos em seres humanos não referentes a medicamentos, em todos esses países, recorre-se às normas éticas formuladas pelas corporações médicas e científicas e que se aplicam a elas mesmas.

A França foi pioneira na Europa, criando, em 1983, um colegiado nacional, o National Consul tative Committee on Ethics for the Life Sciences and Health (CCNE). Na Holanda, durante muito tempo, o Conselho de Saúde exerceu as atribuições de um colegiado nacional de bioética, mas, em 1991, o Dutch Interim Central Committee on Ethical Aspects of Medical Research (KEMO) foi criado para ser o suporte central aos comitês locais de ética médica (Shapiro, 1994).

Na Austrália, a regulamentação dos aspectos éticos da pesquisa em seres humanos é feita por um colegiado nacional, patrocinado pelo equival ente federal do Ministério da Saúde, constituindo o principal organismo financiador de pesquisas médicas (Gillam, 1994). O colegiado é denominado Medical Research Ethics Committee of the National Health and Medical Research Council (NHMRC), ou seja, Comissão de Ética em Pesquisa M édica do Conselho Nacional de Saúde e de Pesquisa Médica.

Em 1982, o NHMRC publicou seus Statement on Human Experimentation, estabelecendo que todas as instituições que conduzem pesquisa médica devem possuir uma Comissão Institucional de Ética, para assegurar que a pesquisa seja conduzida conforme as normas específicas do NHMRC com relação ao consentimento informado, confidencialidade e outros aspectos. Ainda que não tendo força de lei, essas normas foram implementadas com sucesso, em parte porque o NHMRC não financia pesquisas de instituições sem comissão de ética. Em 1988, foi criada a Comissão Consultiva Nacional de Bioética, multidisciplinar, com 
membros da filosofia, do jurídico, da teologia e das ciências biológicas e sociais, com atribuições que vão além das pesquisas com seres humanos.

O Canadá tem desenvolvido uma série de foros em diversos níveis - local, distrital e nacional - para lidar com questões específicas de bioética (Miller, 1994). Existem alguns foros nacionais com mandatos específicos, focalizando tópicos como: aspectos legais, éticos e sociais suscitados pelas tecnologias do genoma; novas tecnologias reprodutivas; experimentações em seres humanos. As associações de profissionais médicos também possuem comissões de ética que têm produzi do documentos com posicionamentos em torno a temas específicos. Apesar da experiência canadense resultar em um emaranhado de recomendações, muitas delas inconsistentes e umas em conflito com outras, esta situação não é interpretada negativamente. Para alguns, este mosaico é positivo, permitindo o amadurecimento de consensos antes de se chegar a uma política nacional mais uniforme, talvez até mesmo embebida em uma legislação.

A partir dos anos 70 e 80, diversos dilemas bioéticos passariam a constituir verdadeiras fontes de estímulo ao desenvolvimento da bioética acadêmica nos Estados Unidos. Comitês de ética proliferaram nos hospitais e em outras instituições de saúde e começaria a ser exigido de cada instituição de pesquisa que possuísse pelo menos uma comissão institucional de revisão ética, para acompanhar as pesquisas em seres humanos financiadas com recursos federais.

$\mathrm{Na}$ visão predominante nos Estados Unidos, as comissões de ética institucionais analisam conteúdos específicos de pesquisas, constituindo verdadeiras instâncias decisórias. Suas sessões, em geral, são públicas, sobretudo quando os pesquisadores são auditados. Estes devem apresentar relatórios, pelo menos uma vez ao ano, sobre os progressos realizados, as mudanças metodológicas introduzidas, os acidentes eventuais etc. As comissões dispõem do poder de revisão dos protocolos de pesquisa, a qualquer momento, daí o nome de Institutional Review Boards. Quando persiste uma discordância entre a comissão de ética e os pesquisadores, uma segunda comissão é constituída para novamente ouvir os pesquisadores e dar um parecer definitivo (Hanna et al., 1993).

Outras comissões foram criadas nos Estados Unidos nos anos 70 e 80 para tratar com tópicos éticos específicos. Entre elas, o Office of Research Integrity (ORI), ligado ao Department of Health and Human Services (HHS). O ORI tem por missão assessorar as instituições de pesquisa, os serviços públicos de saúde, a comunidade científica na análise de alegações de conduta científica inapropriada ou seriamente desviada (falsidade, fabricação, plagiarismo e outros aspectos).

$\mathrm{Na}$ área das pesquisas genéticas, atualmente, antes do início da experimentação clínica, o protocolo de pesquisa deve ser submetido a uma revisão pelo National Institutes of Health Recombinant DNA Advisory Committee (RAC), no caso de receber verbas públicas, e pelo Food and Drug Administration (FDA), em qualquer caso. Nas reuniões públicas de revisão é feita uma apresentação do estado geral dos conhecimentos científicos relativos a cada protocolo específico.

O Office of Technology Assessment (OTA), órgão criado em 1972 para ser um braço analítico do Congresso americano nas questões de ciência e tecnologia, não constituiu, até o presente, comissão de bioética própria. Esta ausência pode ser uma decorrência do mandato, excessivamente amplo, que a OTA recebeu. Devendo realizar avaliações de tecnologias específicas, o tema da bioética está profundamente enraizado na própria natureza da missão institucional da OTA. Da mesma forma, o Institute of Medicine(IOM), criado em 1970-1971, vinculado à National Academy of Sciences, tem incorporado continuamente a bioética em seus diversos e importantes relatórios técnicos e, em 1992, deu início a uma revisão sistemática das comissões de bioética, do passado e atuais, existentes nos Estados Unidos, nas esferas estadual, federal e internacional.

O Congresso americano instituiu, desde 1968, três comissões nacionais dedicadas exclusivamente à bioética: uma Comissão Nacional para Proteção dos Seres Humanos Sujeitos às Pesquisas Biomédica e Comportamental (National Commission), que operou de 1974 até 1978, tendo emitido dez relatórios no período; uma Comissão do Presidente para o Estudo dos Problemas Éticos da Pesquisa em Medicina, Bioética e Comportamental (President's Commission), que funcionou de 1980 até 1983; uma Comissão Assessora em Ética Biomédica (BEAC), que funcionaria apenas no ano de 1988, submergindo no fogo cruzado dos grupos pró e antiaborto.

Nos Estados Unidos, portanto, desde 1988, inexistiu qualquer mecanismo federal dedicado ao debate dos complexos dilemas biomédicos. Recentemente, tanto o Congresso como o Executivo vinham manifestando-se favoravelmente pela necessidade e utilidade de uma comissão nacional para bioética, a ausência da 
mesma sendo percebida como um vazio crítico na política pública daquele país.

A bioética reencontraria uma voz na política pública americana, quando, em outubro de 1995, o Presidente dos Estados Unidos, Bill Clinton, criou a National Bioethics Advisory Commission (NBAC), para estudar os aspectos éticos da pesquisa e o gerenciamento e uso da informação genética. Essa comissão fornecerá assessoria e fará recomendações ao President's National Science and Technol ogy Council e às outras entidades governamentais nos assuntos éticos da pesquisa biológica e comportamental em seres humanos, bem como nas aplicações, clínicas e outras, da pesquisa (Rothenberg, 1995).

Um aspecto de grande interesse para as empresas de biotecnologia e pesquisadores americanos é que a NBAC englobará o tema do patenteamento do genoma humano, tópico não compreendido nas propostas das comissões nacionais anteriores. A NBCA é um comitê assessor não governamental, composto por não mais de 15 membros, indicados pelo Presidente. Sua composição terá membros da filosofia, teologia, ciências sociais/ comportamentais, justiça, medicina e outras profissões da saúde, cientistas e, pelo menos, três membros do público em geral. As agências federais que conduzem, apóiam ou regulamentam pesquisas envolvendo seres humanos, inclusive os departamentos de defesa, energia e saúde, deverão submeter à NBCA os procedimentos que adotam para assegurar a proteção dos indivíduos submetidos às pesquisas. Estas agências deverão arcar com os custos operacionais da NBCA, estimados em dois milhões ao ano.

Merece ser destacado, pela sua importância internacional, o processo regulatório referente ao credenciamento ou licenciamento para a exploração comercial de medicamentos, efetuado pelo Food and Drug Administration FDA. Compete ao FDA fazer intervenções sistemáticas para validação dos resultados de pesquisas, do ponto de vista ético e científico, qualquer que seja o estatuto do laboratório responsável pela experimentação. Nos termos da regulamentação americana, é competência dos pesquisadores fornecer ao FDA as provas de eficácia e segurança do medicamento ou equipamento, fundamentadas nos ensaios laboratoriais e depois em ensaios experimentais em animais e, por último, em seres humanos (Ginzburg, 1992).

O imenso poder regulador do FDA pode ser expresso financeiramente: o órgão regula 25 centavos de cada dólar gasto pelo consumidor americano em bens e serviços, ou seja, cerca de um trilhão por ano. Dando emprego a 9.000 pessoas e com um orçamento de um bilhão, 0 FDA, entretanto, tem sido acusado de retardar o processo de desenvolvimento de drogas e medicamentos nos Estados Unidos, prolongando demasiadamente os estágios pré-aprovatórios da pesquisa farmacêutica (Inman \& Pearce, 1993; Peters, 1994; Kerr, 1995). Por esta razão, existe quem proponha que as funções do FDA sejam privatizadas e que o órgão seja desburocratizado. Os que não concordam com esta proposta argumentam que, com ela, as prescrições dos médicos americanos deixariam de ser administradas pelas políticas de saúde, tornando-se governadas exclusivamente pelo lucro e pelo mercado (The Lancet, 1995).

$\mathrm{Na}$ Inglaterra, existe uma comissão de ética em cada distrito, as Local Research Ethical Committees (LRECS), não havendo uma estrutura nacional, embora o Nuffield Council on Bioethics (Londres) funcione como um comitê nacional. Nos casos de divergência entre pesquisadores e comissão de ética, recorre-se a um árbitro externo, escolhido de comum acordo, ou, quando não é possível, ao organismo profissional concernente (Shapiro, 1994).

A França foi pioneira na adoção de uma legislação nacional cobrindo todos os aspectos da pesquisa biomédica - menos as de matéria psicológica. Razões de ordem moral militaram a favor de um enquadramento jurídico da pesquisa biomédica, resultando na lei de 20 de dezembro de 1988, denominada Lei Huriet, relativa à Proteção das Pessoas que se Apresentam às Pesquisas Biomédicas (Lenoir, 1991; Edelman, 1991; Shapiro, 1994; Champagne \& Marchetti, 1994).

O campo de aplicação da Lei Huriet é amplo, visando a todos os ensaios experimentais praticados em seres humanos, não apenas os de administração de novos medicamentos, como também, entre outros, os referentes à utilização de um novo método de diagnóstico invasivo, de uma nova técnica cirúrgica, de um novo método de aplicação de uma prótese. Visase, da mesma forma, à coleta de informações médicas de ordem particular e de amostras médicas (sangue, biópsia, punção etc). Todos esses atos devem ser, portanto, submetidos à lei, com base no argumento de que extrapolam o interesse imediato do paciente e que o médico, por meio deles, procura ampliar seus conhecimentos médicos.

A chave dessa legislação francesa são as novas estruturas criadas: as comissões de proteção aos indivíduos. Em número de 88, estão presentes em toda a França, cobrindo o conjunto das regiões de modo equilibrado. Devem 
ser criadas pelo Ministro da Saúde e possuir composição multidisciplinar. São compostas por 12 membros titulares e 12 suplentes, sendo oito deles personalidades do meio da pesquisa e da saúde e quatro com qualificação em matéria ética, social, psicológica e jurídica. Os membros são selecionados por sorteio, com base em listas estabelecidas por autoridades diversas e por organizações habilitadas por lei (ordens médicas, de farmacêuticos, associações de portadores de patologias, órgãos de consumidores etc).

Este procedimento não é reproduzido por nenhum outro país e, embora recebendo críticas, constitui forma original de proteção à independência das comissões frente aos grupos de pressão e mandarinatos. O legislador francês teve que separar as comissões de proteção aos indivíduos, exclusivamente competentes em matéria de pesquisa, das comissões de ética. Enquanto estas tratam de casos clínicos, aquelas terão exclusividade na apreciação de protocolos de pesquisa. A ação tutelar do Estado sobre a bioética na França é, portanto, bastante descentralizada.

Vimos que, nos Estados Unidos, além da existência de uma verdadeira malha de comitês institucionais e locais dedicados à bioética, recentemente surgiram várias iniciativas em resposta à necessidade de uma comissão nacional de bioética para arbitrar controvérsias, incluindo a esfera da psicologia e, até mesmo, o patenteamento do genoma humano. Podemos dizer que, enquanto a França adota um modelo legalista, apoiado em uma rede descentralizada de instâncias constituídas pelo Estado para exercer os controles institucionais da bioética, os Estados Unidos adotam um modelo normativo, com uma instância nacional, constituída pelo Estado, para desempenhar o papel de instância de apelação e de arbitragem de controvérsias observadas em uma malha descentralizada de instâncias institucionais de controle da bioética.

\section{Aspectos relevantes a considerar}

\section{Do elitismo}

Os membros de uma comissão de bioética devem ser capazes de poder apreciar os múltiplos aspectos éticos presentes, em toda a sua complexidade, nos mais intrincados tópicos científicos e tecnológicos e nas mais diversas e dissimuladas conformações que podem assumir certas práticas técnicas e políticas. As falhas na compreensão desta complexidade podem re- sultar em recomendações injustas, inapropriadas e não operacionais.

A onipotência dos médicos e dos cientistas deve, entretanto, ser rejeitada, ainda que, para levar adiante uma tal missão, uma comissão de bioética deva, obrigatória e necessariamente, incluir profissionais altamente qualificados. Integrando o, por assim dizer, segmento social de mais elevado nível educacional em uma dada sociedade, estes introduzem o problema do elitismo.

O elitismo se apóia na visão de que, face às desigualdades sociais, é melhor delegar a uma elite selecionada o poder para fazer julgamentos morais em nome de toda a sociedade.

O elitismo profissional pode tornar uma comissão de bioética passível de ser considerada sem legitimidade, por ser composta exclusivamente por membros que, embora sendo qualificados para estabelecer as complexas redes de determinações envolvidas nos aspectos éticos, não necessariamente representarão os valores e os interesses dos demais segmentos sociais. Tanto a onipotência da ciência, quanto a retórica da solidariedade, freqüentemente, são colocadas a serviço de interesses particulares dissimulados.

\section{Da legitimidade}

A adoção do texto da legislação francesa de 20 de dezembro de 1988 sofreu críticas porque apenas alguns deputados a votaram, embora ela seja virtualmente concernente a qualquer cidadão francês. Esta experiência revela que, para ser bem sucedido, um determinado dispositivo legal deve ser amplamente percebido como legítimo.

\section{Da representatividade}

Não deve existir dualidade entre grupos ad hoc de especialistas e um fórum estável multidisciplinar, mas sim uma relação de complementaridade entre ambos. Um fórum estável, criado em resposta às demandas de ordem política, deve levar em conta a representatividade em sua composição. A representatividade poderá assegurar a continuidade e a consistência dos pareceres, quando se tratar de tópicos excessivamente polêmicos ou de temas que tangenciem diretamente com interesses particulares. Um fórum representativo poderá sugerir a convocação, sempre que necessário, de painéis ad hoc de especialistas para assessorar nos julgamentos éticos envolvendo temas específicos. 
Da visão liberal inerente à regulamentação da pesquisa biomédica

A norma bioética tem, inerente a ela, uma visão liberal do corpo humano e da pesquisa científica. Sob o manto da proteção aos direitos do indivíduo, verifica-se, internacionalmente, que, entre os indivíduos submetidos à experimentação médica, a maioria procede de certas "minorias": negros, mulheres, crianças, idosos e pobres (Cooter, 1995).

A norma bioética necessita de interpretações que superem o determinismo da ciência e da técnica. As controvérsias da bioética não emergem de um campo neutro, onde a informação circula livremente entre homens da ciência, interessados apenas em alcançar, por meio dos avanços técnicos, benefícios para a humanidade (Marques, 1991).

A regulação da bioética diz respeito tanto a processos internos à ciência quanto a processos econômicos, políticos e culturais. Com freqüência, cientistas, médicos e representantes da indústria somam esforços na defesa de determinados interesses comuns entre eles, mas nem sempre coincidentes com os interesses públicos.

A controvérsia éa tônica no campo não neutro da bioética. É nesse contexto, atravessado por interesses econômicos, que a pesquisa em seres humanos é real izada, sem que se supere a enorme contradição presente no fato de que indivíduos-cidadãos são legal e moralmente autorizados a submeter seus corpos e mentes para o avanço da ciência, conquanto isto se dê voluntariamente, isto é, com seu consentimento informado.

\section{Sugestões para o modelo regulatório da bioética no Brasil}

As experências recentes de outros países ensinam que a discussão da bioética no Brasil terá que responder às seguintes indagações de ordem geral:

1) O Estado Brasileiro deverá estabelecer uma Lei para a bioética?

2) O Estado Brasileiro deverá constituir uma comissão nacional de bioética, com câmaras setoriais, tendo em conta os princípios da legitimidade e da representatividade? Esta comissão, em sendo constituída pelo Estado, deverá receber o mandato para coordenar a elaboração e a atualização de orientações normativas para os diversos aspectos da bioética? Esta comissão deverá assumir a atribuição de instância federal de apelação e apoio a uma rede de comissões locais e institucionais, sempre quando for necessário arbitrar controvérsias éticas?

3) O Estado Brasileiro deverá fomentar a criação da rede brasileira de comissões de ética de pesquisa e introduzir uma sistemática de credenciamento?

No âmbito do setor saúde, consideramos que será fundamental constituir uma instância de abrangência nacional, legítima, representativa e independente, com mandato do governo brasileiro para arbitrar controvérsias e conflitos de interesses, suscitados pela conduta ética, na investigação biomédica; também será fundamental haver um grande desenvolvimento de comitês locais de bioética por todo o Brasil. No caso de resposta afirmativa à primeira questão, o Estado Brasileiro estará optando por um modelo legalista, semelhante ao da França e que somente será viabilizado se apoiado em uma rede descentralizada e regionalizada de comissões locais de bioética. A opção pelo modelo legalista, sem dúvida, cumprirá um importante papel na defesa da integridade ética da pesquisa em saúde no Brasil, sobretudo tendo em conta que a quase totali dade dela é realizada com recursos públicos.

Pensamos que a regulamentação federal deverá assegurar a necessária autonomia e flexibilidade para o desenvolvimento da ciência no Brasil, evitando uma rigidez regulatória que poderá vestir as iniciativas científicas com uma "camisa-de-força".

Quanto ao credenciamento, consideramos que, no modelo brasileiro, alguns comitês locais poderão ser designados pelo Governo Federal para desempenhar as funções de comitês regionais de ética em pesquisa. No caso das pesquisas biomédicas, clínicas e epidemiológicas envolvendo seres humanos, caberia ao Ministério da Saúde efetuar tais designações, ouvido o Conselho Nacional de Saúde e/ ou os Conselhos Estaduais e Municipais de Saúde. Com isto, os comitês regionais passariam a examinar protocolos de pesquisas envolvendo seres humanos e emitiriam pareceres, atendendo às solicitações externas procedentes da sua região.

O importante, a nosso ver, é que os indivíduos envolvidos nas pesquisas sejam sempre protegidos por comitês locais de ética em pesquisa, os quais devem operar sob regulamentação federal mínima. Por último, defendemos o ponto de vista de que a integridade ética de pesquisas feitas em seres humanos no Brasil somente estará assegurada se a criação de comissões de ética em pesquisa passar a ser obrigatória. O Governo Federal estabelecerá os prérequisitos indispensáveis para o registro e o re- 
conhecimento da legitimidade dos comitês de ética em pesquisa, bem como o prazo de validade do credenciamento e os procedimentos a serem seguidos nas apelações ou recursos, referentes aos resultados da análise do protocolo da pesquisa envolvendo seres humanos.

Em síntese, o Governo Federal será responsável pelo cadastramento, pela coordenação, pela orientação normativa, pela explicitação das responsabilidades e delegação de atribuições, pela fiscalização e pela avaliação sistemática das comissões locais de revisão bi oética nos níveis nacional, regional e local. Caberá ao Governo Federal definir as sanções e penalidades que serão aplicadas às instituições, organizações, pesquisadores, patrocinadores e promotores nos casos de transgressão aos princípios e normas bioéticas, bem como definir os procedimentos para formalização de denúncias referentes às pesquisas envolvendo seres humanos e referentes à atuação dos comitês locais.

Este modelo reconhece o comitê local como o principal mecanismo de revisão bioética de pesquisas no País, pela sua proximidade e/ ou familiaridade com as condições e circunstâncias sob as quais se real izam determinadas pesquisas. O comitê local pode e deve trabaIhar junto ao pesquisador para garantir os direitos e o bem-estar dos indivíduos envolvidos e, ao mesmo tempo, assegurar que a aplicação de políticas governamentais, institucionais ou das empresas sejam justas com os pesquisadores, principalmente no que se refere à liberdade de criação e de crítica. Outras vantagens do comitê local é que poderá se constituir em um mecanismo estimulador da participação dos pesquisadores e das comunidades locais em temas de natureza ética, podendo se tornar um verdadeiro centro de informação em ética, construindo bases de dados específicas, sobretudo de documentos regulatórios diversos.

Na perspectiva aqui introduzida para o modelo do Brasil, a atividade regulatória expressará um mínimo de intervenção federal sobre a autonomia dos comitês locais de bioética. Este mínimo compreenderá a criação compulsória dos comitês locais. Essa medida será, sem dúvida, eficaz para assegurar que os comitês locais de revisão bioética passem a fazer parte da cultura das instituições públicas e das organizações privadas no País.

\section{Compatibilizações necessárias}

Optando-se no Brasil pelo modelo legalista, semelhante ao da França, será preciso compatibilizar a intervenção regulatória da bioética com a Lei 8.974, de janeiro de 1995, conhecida como Lei da Biossegurança. Esta lei, antecipando-se ao processo de revisão deflagrado pelo Conselho Nacional de Saúde, constituiu uma instância colegiada, a Comissão Técnica Nacional de Biossegurança - CTNBio, composta por especialistas e representantes de vários setores do governo.

Indo além da biossegurança, contempla alguns aspectos importantes da bi oética, vedando e caracterizando como crimes: a manipulação genética de células germinais humanas; a intervenção em material genético humano in vivo, exceto para tratamento de defeitos genéticos; a produção, armazenamento ou manipulação de embriões humanos. As penas de detenção previstas variam de três meses a vinte anos.

A Lei 8.974/95, portanto, conferindo um tratamento horizontal à engenharia genética, adentra no terreno de complexas questões da bioética contemporânea que dizem respeito aos seres humanos.

Considerando o atual estado da arte, em especial no caso das novas técnicas genéticase de reprodução assistida, pensamos que o Brasil, antecipando-se às discussões internacionais em curso sobre a dimensão regulatória da bioética, optou por uma lei bastante restritiva. Para nós, à medida que a Lei 8.974/ 95 for sendo aplicada, se não existirem discussões aprofundadas e atualizadas, não apenas nos meios acadêmicos, mas na sociedade em geral, poderão florescer as simplificações analíticas de diversa ordem, diante da percepção de riscos potencias; poderão ser criadas dificuldades, no País, à flexibilidade crítica em certas áreas acadêmicas que experimentam, internacionalmente, transformações muito velozes; fatos e temas da ciência poderão ser remetidos para a interpretação da justiça, sem que esta tenha familiaridade com os mesmos.

Vimos que, para certos países, as leis não são instrumentos adequados para a intervenção regulatória sobre a bioética e alguns consideram saudável a convivência com um emaranhado de normas e regulamentos para os diversos tópicos da bioética. Não consideram apropriado ignorar as diversas e, muitas vezes, disparatadas visões existentes no campo da bioética, sobretudo tendo em conta a inexistência de consensos nas discussões internacionais sobre a nova genética e sobre a vida.

Outra questão a destacar refere-se às interfaces público/privado. Em trabalho anterior (Marques, 1993), desenvolvemos a hipótese de que as novas tecnologias têm acirrado as controvérsias e conflitos de interesse nas relações 
entre ciência, governo e empresas privadas, fazendo com que as discussões sobre os interesses nacionais - um conceito, por si mesmo, limitado no plano teórico, nos estudo das relações internacionais - caracterizem-se pela arbitrariedade. O caráter estratégico das novas tecnologias também tem conduzido a discussão da responsabilidade pública das universidades para o centro dessas controvérsias (Kaiser, 1995; Swinnerton-Dyer, 1995; Mudur, 1995; Mervis, 1995; Nowak, 1994).

Na experiência da CICT/CNS com a Resolução 1/88, pudemos observar que conflitos de interesses emergiam a todo instante, evidenciando que, no campo da pesquisa biomédica e clínica, a discussão dos limites entre o público e o privado deverá ser priorizada na regulamentação ética da pesquisa realizada com fundos públicos e com a participação do setor privado.

Para prevalecer sobre os interesses meramente privados, uma política pública deve, necessariamente, estimular a confluência de interesses públicos e privados no alcance de objetivos comuns. Sempre que pesquisas universitárias são feitas fora desse marco de política pública, de capacitação científica e tecnológica, servem apenas para chancelar interesses privados e, o que é grave, às custas de recursos públicos. Desse modo, a instância nacional de apelação cumprirá um importante papel na defesa da integridade ética da pesquisa em saúde no Brasil, tendo em conta, principalmente, que a quase totalidade dela é realizada com recursos públicos.

A adoção de uma sistemática de credenciamento, aplicável à realização de certos ensaios clínicos com medicamentos e equipamentos envolvendo seres humanos, introduzirá um mecanismo de controle rigoroso do Estado, evitando o laissez-faireacadêmico e empresarial. Além de estabelecer a criação compulsória de mecanismos de proteção à integridade ética nas instituições que realizam pesquisas com seres humanos (comissões de bioética), essa sistemática também poderá ser um recurso indutor de projetos estratégicos de articulação universidade-institutos de pesquisa-empresas.

Acreditamos que a fragilidade da capacitação endógena do Brasil em matéria da P\&D industrial farmacêutica, embora sendo, a nosso ver, um motivo suficiente, não tem estado na base da regulação econômica das pesquisas biomédicas e clínicas, com fármacos e medicamentos e com equipamentos e dispositivos médicos. Parece-nos claro que, tendo em conta a fragilidade endógena nesta área, caberia ao órgão responsável pelo registro, vigilância e con- trole de fármacos e medicamentos coordenar o processo de credenciamento de centros de pesquisas em farmacologia clínica em território nacional e introduzir uma lógica de política pública nesse processo, vinculando credenciamento e prioridades da política de saúde.

O Estado Brasileiro, representado pelo Ministério da Saúde, passaria, assim, a conferir aos centros credenciados um mandato para realização de ensaios em seres humanos, em áreas específicas, em atendimento às claras demandas das políticas públicas.

A idéia do credenciamento de centros ou instituições será, portanto, defensável se enquadrada em uma perspectiva de política pública que, adotando a abordagem sistêmica, estimule a constituição de redes descentralizadas de instituições credenciadas para a realização de certos programas e projetos de pesquisas com financiamento público e que, como tal, deverão dispor de comissões institucionais de bioética e de biossegurança.

É preciso evitar quer a excessiva intervenção do Estado sobre a ciência, quer a constituição de uma verdadeira malha de cartéis de pesquisas em saúde envolvendo seres humanos. Estas duas possibilidades provocariam, com certeza, impactos negativos para a expansão da capacitação científica e tecnológica em saúde do Brasil. Não consideramos desejável, portanto, uma generalização acrítica ou uma introdução horizontal, compulsória e meramente fiscalizatória dessa sistemática de credenciamento para todas as áreas acadêmicas em nosso País.

\section{Considerações finais}

Com base na revisão apresentada neste documento, podemos afimar que, no Brasil, estamos dando os primeiros passos em direção ao amadurecimento da ciência regulatória no campo da bioética. A escolha de procedimentos regulatórios para a bioética deverá ter em conta as implicações dos mesmos, a curto, médio e longo prazo, para o desenvolvimento da Ciência no País e para um conjunto de opções estratégicas no campo da Saúde, considerando, acima de tudo, as transformações paradigmáticas e muito velozes que, neste final de século, experimentam as biotecnologias de terceira geração e as ciências da informação e comunicação (Marques, 1989; Possas et al, 1994).

É preciso não perder de vista que, internacionalmente, em especial nos Estados Unidos e nos países da União Européia, ainda está havendo um amadurecimento da ciência regula- 
tória deste domínio, que é uma junção da experiência científica com a experiência da política pública (Jasanoff, 1995). Nessas experiências, existe um crescente reconhecimento de que a apreciação ética preventiva é um recurso para ser utilizado caso a caso, projeto a projeto, para que os limites entre a ciência e a política possam ser delineados, usando-se o bom senso em situações particularmente complexas para a tomada de decisão.

Finalizando, esperamos que, no Brasil, a ação regulatória sobre a bioética seja acoplada à política pública em saúde e, principalmente, ao processo de planejamento estratégico do desenvolvimento da capacitação científica e tecnológica em saúde.

\section{Referências}

ANNAS, G. J., 1995. Editorial: Genetic prophecy and genetic privacy - can we prevent the dream from becoming a nigthmare? American Journal of Public Health, 85:1196-1197.

BREWIN, T., 1994. Primum non nocere? The Lancet, 344:1487-1488.

BURKE, D. C., 1995. Genetic manipulation: public opinion, political attitudes and commercial prospects - an introdutory lecture. Journal of Applied Bacteriology, 79(suppl.):1S-4S.

BUTLER, D., 1995. News: Europe dilutes draft bioethics conventio. Nature, 373:466.

CARLINI, E. A., 1987. Pesquisas Fármaco-Clínicas no Brasil: Ética e Normalização. São Paulo: AFP.

CHAM PAGNE, P. \& MARCHETTI, D., 1994. L'information médicale sous contrainte. A propos du scandale du sang contaminé. Actes de La Rechercheen Sciences Sociales, Mars:40-62.

CIOMS/ OMS (Consel ho das Organizações Internacionais das Ciências Médicas/Organização Mundial da Saúde), 1995. Diretrizes éticas internacionais para pesquisas biomédicas envolvendo seres humanos. Bioética, 3:95-136.

CNS (Conselho Nacional de Saúde), 1995a. Resolução Número 1, de 1988. Brasília: CNS.

CNS (Conselho Nacional de Saúde), 1995b. Atas das Reuniões Plenárias do Conselho Nacional de Saúde do ano de 1995. Brasília: CNS.

CNS (Conselho Nacional de Saúde), 1995c. Resolução Número 173, de novembro de 1995. Brasília: CNS.

CNS (Conselho Nacional de Saúde), 1995d. Resolução Número 170, de novembro de 1995. Brasília: CNS.

COLE, P., 1995. The moral bases for public health interventions. Epidemiology, 6:78-83.

COLE-TURNER, R., 1995. Religion and gene patenting. Science, 270:52.

COOTER, R., 1995. The resistible rise of medical ethics. Social History of Medicine, 8:257-270.

COUGHLIN, S. S. \& ETHEREDGE, G. D., 1995. On the need for ethics curricula in epidemiology. Epidemiology, 6:566-567.
DODET, B., 1994. Industrial perception of EC biotechnology regulations. Trends in Biotechnology, 12: 473-476.

EDELM AN, B., 1991. Expérimentation sur I'homme: une loi sacrificielle. La Recherche, 22:1.056-1.065.

GARRAFA, V., 1995. A Dimensão da Ética em Saúde Pública. São Paulo: Faculdade de Saúde Pública, Universidade de São Paulo.

GILLAM, L., 1994. Bioethics and public policy in Australia. Politics and the Life Sciences, 3:87-88.

GINZBURG, H. M., 1992. The legal perspective. Investigacional new drugs: FDA regulatory policy. $\mathrm{Pe}$ diatric AIDS and HIV Infection: Fetus to Adolescent, 3:202-212.

HANNA, K. E.; COOK-DEEGAN, R. M. \& NISHIMI, R., 1993. Finding a fórum for bioethics in U.S. Public Policy. Politics and the Life Sciences, 12:205-219.

HARPER, P. S., 1995. Genetic testing, common diseases, and health service provision. The Lancet, 346:1.645-1.646.

HUDSON, K. L.; ROTHENBERG, K. H.; ANDREWS, L. B.; KHAN, M. J. E. \& COLLINS, F. S., 1995. Genetic discrimination and health insurance: an urgent need for reform. Science, 270:391-393.

INMAN, W. \& PEARCE, G., 1993. Prescriber profile and post-marketing surveillance. The Lancet, 342: 658-661.

JASANOFF, S., 1995. Procedural choices in regulatory science. Technology in Society, 17:279-293.

KAISER, J., 1995. Commission proposes new definition of misconduct. Science, 269:1811.

KEATS, T., 1995. Bioethics in Italy. The Lancet, 345: 182.

KERR, R. A.,1995. AIDS researchers, activists fight crisis in clinical trials. Science, 269:1.666-1.667.

KOENIG, R. L., 1995. Biotech regulations: Germany loosens some red tape. Science, 267:326.

LENOIR, N., 1991. Aux Frontières de la Vie: Une ÉthiqueBiomédicaleà la Française. Paris: La Documentation Française.

MACER, D. R. J., 1994a. Bioethics for the People by the People. Christchurch: Eubios Ethics Institute. 
MACER, D. R. J., 1994b. Bioethics may transform public policy in Japan. Politics and the Life Sciences, 13:89-90.

MARQUES, M. B., 1989. Limites ao Desenvolvimento Científico e Tecnológico em Saúde no Brasil. Rio de Janeiro: NECT/CICT/Fiocruz.

MARQUES, M. B., 1991. Ciência, Tecnologia, Saúde e Desenvolvimento Sustentado. Rio de Janeiro: NECT/CICT/Fiocruz.

MARQUES, M. B., 1993. Patenting Life. Foundations of the Brazil-United States Controversy. Rio de Janeiro: NECT/CICT/Fiocruz.

MARQUES, M. B., 1994. Brazil-United States controversy on the impact of patenting in biotechnology: some relevant questions for pharmaceuticals. Science and Public Policy, 21:165-172.

MCSHANE, R.; HOPE, T. \& WILKINSON, J., 1994. Tracking patients who wander: ethics and technology. The Lancet, 343:1274.

MERVIS, J., 1995. Conflict of interest: final rules put universities in charge. Science, 269:294.

MICHAELIS, A. R., 1995. ISR Editorial: The ethical dilemma. Interdisciplinary Sci ence Revi ews, 20: 85-87.

MILLER, J., 1994. What to do untill the philosopher kings come: bioethics and public policy in Canada. Politics and the Life Sciences, 3:93-95.

MUDUR, G., 1995. New rules push researchers closer to biotech industry. Science, 269:297-298.

NATURE, 1995. Opinion: Genome diversity alarms. The excellent Human Genome Diversity Project needs better planning and a pilot project. Nature, 377:372.
NOWAK, R., 1994. Problems in clinical trials go far beyond misconduct. Science, 264:1538-1541.

OLSON, M., 1995. A time to sequence. Science, 270: 394-396.

ORKIN, S. H. \& M OTULSKY, A. G., 1995. Report and Recommendations of the Panel to Asses the NIH Investment in Research on GeneTherapy. Washington DC: National Institutes of Health Recombinant DNA Advisory Committee.

PESSINI, L. \& BARCHIFONTAINE, C. P., 1994. Proble mas Atuais de Bi oética. São Paulo: Edições Loyola.

PESSINI, L., 1995. O desenvolvimento da bioética na América Latina. Saúdeem Debate, 47:57-66.

PETERS, E., 1994. Gene technology between deregulation and bureaucracy. Interdisciplinary Science Review, 19:10-11.

POSSAS, M. L.; SALLES FILHO, S. \& MELLO, A. L. A., 1994. O Processo de Regulamentação da Biotecnologia: as Inovações na Agricultura ena Produção Agroalimentar. Brasília: IPEA.

ROTHENBERG, L., 1995. Bioethics commission to review gene patenting. Bio/Technology, 13:1431.

SEGRE, M. \& COHEN, C., 1995. Bioética. São Paulo: Edusp.

SHAPIRO, D., 1994. A single national voice for bioethics: reflections from Europe. Politics and the Life Sciences, 3:98-99.

SWINNERTON-DYER, P., 1995. The importance of academic freedom. Nature, 373:186-188.

THE LANCET, 1995. Editorial: In defense of the FDA. The Lancet, 346:981.

WHARTENBY, K. A.; MARROGI, A. J. \& FREEMAN, S. M., 1995. Gene therapy. Clinical potential and relationships to drug treatment. Drugs, 50:951-958. 